Int. J. Electrochem. Sci., 14 (2019) 10070 - 10078

\title{
Sensitive Electrochemical Determination of Adenosine-5'- triphosphate with 1-Butyl-2,3-dimethylimidazolium Hexafluorophosphate Based Carbon Paste Electrode
}

\author{
Lili Wei ${ }^{1}$, Hui Cheng ${ }^{2}$, Yong Chen ${ }^{2}$, Juan Liu' ${ }^{2}$, Shaohui Jia ${ }^{3, *}$, Wei Sun ${ }^{2}$ \\ ${ }^{1}$ Department of Life Science and Engineering, Jining College, Qufu 273155, P R China \\ ${ }^{2}$ College of Chemistry and Chemical Engineering, Hainan Normal University, Haikou 571158, P R \\ China \\ ${ }^{3}$ School of Basic Medicine, Jining Medical University, Jining 272067, P R China \\ *E-mail: 14195070@qq.com
}

doi: $10.20964 / 2019.11 .21$

Received: 3 June 2019 / Accepted: 7 August 2019 / Published: 7 October 2019

\begin{abstract}
A new voltammetric procedure was established for the analysis of adenosine-5'-triphosphate (ATP) with ionic liquid 1-butyl-2,3-dimethylimidazolium hexafluorophosphate $\left(\mathrm{BMMImPF}_{6}\right)$ based carbon paste electrode $(\mathrm{CPE})$. The modification of high conductive $\mathrm{BMMImPF}_{6}$ in $\mathrm{CPE}_{\text {decreased the }}$ interfacial resistance and provided good electrocatalytic activity to accelerate the oxidation of ATP with the increment of the oxidation peak current. A well-defined irreversible oxidation peak of ATP was observed at $1.42 \mathrm{~V}$ in a $\mathrm{pH} 3.0$ Britton-Robinson (B-R) buffer solution with an adsorptioncontrolled process, which was due to the interaction of ATP with the imidazolium group of ionic liquid used. The experimental conditions were optimized with the accumulation time of $80 \mathrm{~s}$ and the accumulation potential of $0.3 \mathrm{~V}$. Under the optimum conditions with differential pulse voltammetry, the oxidation peak current showed a good linear relationship with ATP concentration from 0.3 to 700.0 $\mu \mathrm{mol} / \mathrm{L}$ with the detection limit as $0.912 \mathrm{nmol} / \mathrm{L}(3 \mathrm{~S} / N)$. This method was not disturbed by the interferences from commonly coexisting compounds, which was applied to detect the drug samples with good recovery.
\end{abstract}

Keywords: Carbon paste electrode; Adenosine-5'-triphosphate; Voltammetry; 1-butyl-2,3dimethylimidazolium hexafluorophosphate

\section{FULL TEXT}

(C) 2019 The Authors. Published by ESG (www.electrochemsci.org). This article is an open access article distributed under the terms and conditions of the Creative Commons Attribution license (http://creativecommons.org/licenses/by/4.0/). 